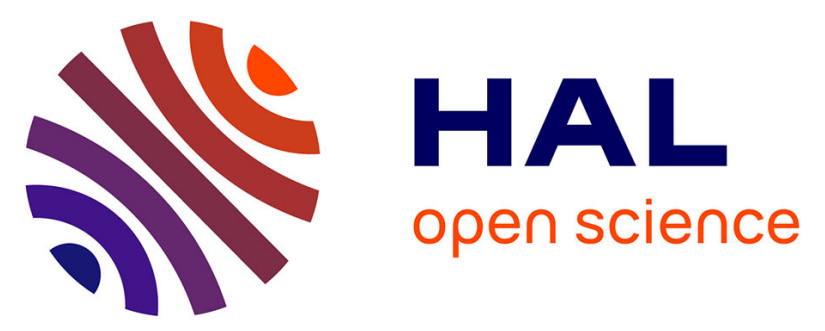

\title{
Bubble size and liquid-side mass transfer coefficient measurements in aerated stirred tank reactors with non-Newtonian liquids
}

\author{
Vincenzo Cappello, Cécile Plais, Christophe Vial, Frédéric Augier
}

\section{To cite this version:}

Vincenzo Cappello, Cécile Plais, Christophe Vial, Frédéric Augier. Bubble size and liquid-side mass transfer coefficient measurements in aerated stirred tank reactors with non-Newtonian liquids. Chemical Engineering Science, 2020, 211, pp.115280. 10.1016/j.ces.2019.115280 hal-02447708

\section{HAL Id: hal-02447708 \\ https://hal-ifp.archives-ouvertes.fr/hal-02447708}

Submitted on 23 Jan 2020

HAL is a multi-disciplinary open access archive for the deposit and dissemination of scientific research documents, whether they are published or not. The documents may come from teaching and research institutions in France or abroad, or from public or private research centers.
L'archive ouverte pluridisciplinaire HAL, est destinée au dépôt et à la diffusion de documents scientifiques de niveau recherche, publiés ou non, émanant des établissements d'enseignement et de recherche français ou étrangers, des laboratoires publics ou privés. 


\title{
Bubble size and liquid-side mass transfer coefficient measurements in aerated stirred tank reactors with non-Newtonian liquids
}

\author{
Vincenzo Cappello ${ }^{\mathrm{a}, \mathrm{b}}$, Cécile Plais ${ }^{\mathrm{a}}$, Christophe Vial $^{\mathrm{b}}$, Frédéric Augier ${ }^{\mathrm{a}}$ \\ ${ }^{a}$ IFP Energies Nouvelles, Rond-point de léchangeur de Solaize, BP 3, 69360 Solaize, \\ France \\ ${ }^{b}$ Université Clermont Auvergne, CNRS, Sigma Clermont, Institut Pascal, F-63000 \\ Clermont-Ferrand, France
}

\begin{abstract}
Oxygen transfer is a key element in aerobic fermentations, especially if the culture broth's rheology is non-Newtonian, as in the case of cultures of filamentous fungi. It is well known that viscosity negatively affects the volumetric mass transfer coefficient $\left(k_{L} a\right)$, but mechanisms involved in terms of change of interfacial area $(a)$ and liquid-side mass transfer coefficient $\left(k_{L}\right)$ have still not been clearly identified. This lack of knowledge is in part due to the difficulty in measuring bubble size in aerated media, especially in viscous fluids. In the present study, a recently developed dual-probe method was validated and then used to measure bubble Sauter mean diameter $\left(d_{32}\right)$ in water and in xanthan gum solutions, which exhibit rheological behaviors similar to filamentous fungi's broths. Ethanol was used to modify the coalescence of the dispersed phase and the results were compared to data obtained in a filtered fermentation culture of Trichoderma reesei. Additional experiments were carried out to obtain the volumetric mass transfer coefficient and the global gas holdup $\left(\alpha_{G}\right)$. It was then possible to obtain the liquid-side
\end{abstract}


mass transfer coefficient and to compare it with existing models. Finally, empirical correlations were proposed to estimate $d_{32}, \alpha_{G}, k_{L} a$ and $k_{L}$ in a mechanically stirred tank. It was observed that $k_{L}$ depended only on the apparent viscosity of the system, unlike all the other measured properties $\left(k_{L} a, d_{32}, \alpha_{G}\right)$ which were very sensitive to power consumption, superficial gas velocity, viscosity and the presence of additives.

Keywords: Multiphase reactor, Bioreactor, Mass transfer, Bubble size, Non-Newtonian fluid

\section{Introduction}

The scale-up of aerated bioreactors is a complex area of research, which has been widely studied for decades (Paul et al. (2004), Garcia-Ochoa and Gomez (2009)). Among the variety of aerobic cultures performed in agitated tanks, the framework of the present study is the scale-up of filamentous fungi cultures, which have recently been used in the production of enzymes. In particular, the fermentation of Trichoderma reesei, due to its high-yield secretation of cellulase, is a key step in the production of lignocellulosic ethanol, in which these enzymes are used to extract fermentable sugars contained in the lignocellulose (Gabelle et al. (2012), Hardy et al. (2017)). As a consequence, bioreactors of several hundred cubic meters or more, may be designed and operated in the future to reduce the production cost of enzymes and then of biofuels. Trichoderma reesei's culture has some peculiarities: highly viscous non-Newtonian broth and high oxygen demand. These two specificities require high power supply in the bioreactor in order to enhance mass transfer $\left(k_{L} a\right)$; however, this fungus strain is also shear sensitive (Hardy et al. (2017)), 
so particular care has to be taken in the choice of the mixing technology and operating conditions.

A first set of engineering tools that can help perform the scale-up of such processes is composed of correlations able to predict the majority of impacting parameters such as: dissipated power, gas holdup, mass transfer coefficient, and mixing time (Garcia-Ochoa and Gomez (2009), Gabelle et al. (2011), Petříček et al. (2018)). This approach is necessary to design industrial-scale bioreactors, but it is hazardous, as the empirical correlations are usually validated only at scales much smaller $\left(\sim 0.001-0.1 \mathrm{~m}^{3}\right)$ than the scale that is commonly encountered in industry $\left(\sim 100-300 \mathrm{~m}^{3}\right)$. Therefore, further validations at the intermediary scales are needed. Another limitation of this strategy is that it overlooks the local inhomogeneity in $\mathrm{pH}$, temperature, concentration of substrates (if any), and other process parameters.

To provide a more local description of physical and biological mechanisms involved, Computational Fluid Dynamics (CFD) has been used to simulate flow inside bioreactors, and to couple hydrodynamics modeling with transport of substrate and its consumption by the microorganisms (Lapin et al. (2006), Delvigne et al. (2017), Haringa et al. (2017)). While using CFD, bubble size becomes a key parameter to describe both the hydrodynamics and mass transfer phenomena. For this reason, many studies have been conducted to estimate the bubble size in stirred reactors, mainly in water and at low gas velocity (Barigou and Greaves (1992), Machon et al. (1997), Bouaifi and Roustan (1998), Alves et al. (2002); Montante et al. (2008)). If non-Newtonian systems in stirred vessels are considered, available data is much more limited, and existing empirical correlations are derived from the- 
oretical considerations (Garcia-Ochoa and Gomez (2009)). As pointed out by Momiroski et al. (2018), current techniques are not suitable to measure bubble size in highly viscous and opaque fluids in aerated stirred tanks. In their work, they measured the bubble size in the impeller discharge region in shear-thinning solutions; however, the maximum superficial gas velocity they investigated was relatively low, equaling $3 \mathrm{mms}^{-1}$. Alternatively, Bach et al. (2017) used CFD simulations to overcome the need for bubble size measurements in viscous broths, which is an interesting approach, provided that the mass transfer is correctly modeled.

Recently, an original technique to estimate bubble size in turbulent flows was developed Raimundo et al. (2016)). The technique is based on the spatial cross-correlation (CC) between the signals measured by two phase-detective optical probes, whose tips are in the same horizontal plane and are separated by a distance of $600-800 \mu \mathrm{m}$. This method was originally validated in dense air-water flows in bubble columns, and it provides the local Sauter mean diameter. However, with this technique no information about bubble velocity and bubble size distribution can be obtained.

Therefore, the first objective of this study was to validate the CC technique in a stirred reactor filled with a non-Newtonian model fluid. The validation was done in transparent solutions of carboxymethyl cellulose (CMC) by comparing CC results with measurements from image analysis. In a second step, the dual-probe was used to characterize xanthan gum (XG) aqueous solutions at different concentrations. These polymeric solutions are opaque and exhibit rheological behaviors closer to Trichoderma reesei broths (Gabelle et al. (2011)). Results of bubble size measurements were completed with 
global gas holdup and volumetric mass transfer coefficient data obtained at different operating conditions. All the experiments were performed in a standard flat-bottom tank equipped with a six-blade Rushton turbine and four baffles.

Since fermentation broths contain proteins and nutrients that act as surfactants, bubble size measurements were also carried out in a filtered fermentation broth. This medium is neither stable nor easily reproducible; consequently, the fermentation culture is not suitable to develop models. To mimic the blocking of coalescence in the broth, small amounts of ethanol were dissolved in model fluids, as Gemello et al. (2018) reported that even at a concentration of $0.05 \%$, ethanol caused a notable decrease of bubble sizes, hindering air bubbles' coalescence in air-water bubble columns.

Finally, experimental results were analyzed and empirical correlations suggested. Bubble size measurements were compared to different equations available in the literature. As gas holdup and bubble size appeared to be almost uniform in the tank, the average liquid-side mass transfer coefficient could be deduced from the measurement of the volumetric mass transfer coefficient, gas holdup, and bubble size. Furthermore, the values of $k_{L}$ so obtained were compared to some existing theoretical models. The effect of ethanol on bubble size, holdup, and volumetric and liquid-side mass transfer coefficients was also discussed.

\section{Experimental setup}

Experiments were carried out in a cylindrical glass tank with a flat bottom and a diameter $T=0.3 \mathrm{~m}$ (Figure 1 ). The vessel was filled up to a height 
$H$ equal to its diameter, for a total volume $V$ of $0.021 \mathrm{~m}^{3}$. Agitation was provided by a single six-blade Rushton turbine with a diameter $D=T / 3$, placed at a distance $h_{D}=T / 3$ from the bottom of the vessel. The tank was also equipped with four equispaced rectangular baffles and a $0.06 \mathrm{~m}$ diameter ring sparger, which was located about midway between the impeller and the bottom $\left(h_{S}=T / 5\right)$. Air entered the system through 21 holes of $1 \mathrm{~mm}$ of diameter, homogeneously distributed on the sparger. The gas flow rate was varied in order to have superficial gas velocity $\left(U_{G}\right)$ in the range $4-40 \mathrm{~mm} \mathrm{~s}^{-1}$, i.e. $0.8-8 \mathrm{vvm}$, while the impeller speed $(N)$ ranged between 6 and $16.6 \mathrm{~s}^{-1}$. The relative power draw (RPD) was calculated with the correlation proposed by Gabelle et al. (2011), which was validated at the same operating conditions used in this study, with an accuracy of $10 \%$

$$
\frac{P_{G}}{P_{0}}=\max \left[\left(\frac{P_{G}}{P_{0}}\right)_{l i m} ; \exp \left(-15.36 N_{P}^{0.16} Q_{G}^{0.62} T^{-1.7}\left(\frac{D}{T}\right)^{0.51}\right)\right]
$$

where $N_{P}$ is the power number calculated with the correlation of Bujalski et al. (1987), $Q_{G}$ the gas flow rate in $\mathrm{m}^{3} \mathrm{~s}^{-1}$, and $\left(P_{G} / P_{0}\right)_{l i m}$ the constant value of RPD at high gas flow rate (Paul et al. (2004)), which depends on the geometry of the impeller. For a configuration with a single Rushton turbine, Gabelle (2012) measured a value of 0.33 .

\subsection{Model fluids}

At the end of fermentation, the liquid phase of Trichoderma reesei contains a considerable amount of proteins - mainly cellulase, but also hydrophobins that act as surfactants (Cox et al. (2009), Tchuenbou-Magaia et al. (2009)) — and additives (pH regulator, antifoam agents, etc.), which have an impact on the mass transfer rate because of their effect on bubble 


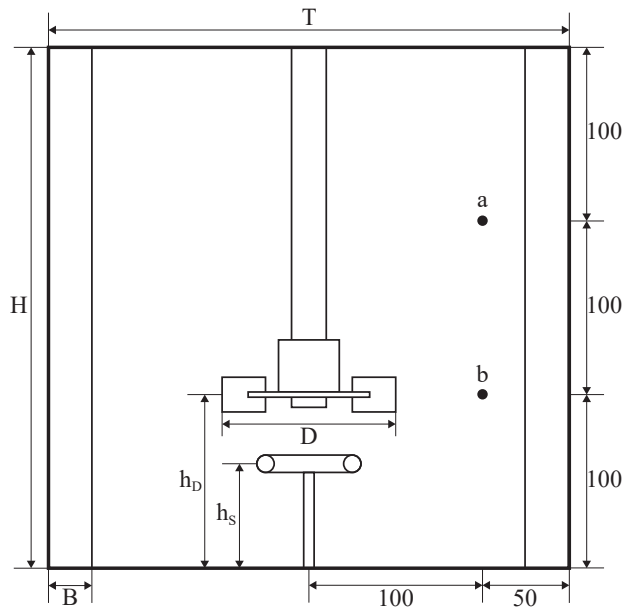

Figure 1: Details of the vessel used in the experiments. The length of the baffles $B$ was equal to $D / 5$. Locations of the optical dual-probe (a) and the oxygen probe (b) are highlighted.

coalescence and interface phenomena. However, because of its composition, the fermentation broth is scarcely reproducible and a model fluid is more suitable to quantify the effects of rheology and surfactants. In the case of filamentous fungi, rheology is strictly linked to the concentration of the microorganisms, which changes during fermentation. The presence of this solid suspension in the liquid prevented the use of the cross-correlation technique in the fermentative medium. Filtration of the culture broth made the measurement possible, but the rheological properties got lost. Gabelle et al. (2012) measured the viscosity during the fermentation of Trichoderma reesei, showing that xanthan gum (XG) solutions at different concentrations can be used to reproduce the rhelogical behavior of the broth during its fermentation. Two mass concentrations of the polymer were used in this study: $025 \%$ and $050 \%$. The latter had a rheology very similar to the broth's at 
the end of the fermentation process. When dissolved in water, XG creates an opaque solution, so it could not be used to validate the bubble size measurement technique. During the first part of this study, carboxymethyl cellulose (CMC) at concentration $025 \%$ and $050 \%$ was used instead.

The aqueous solutions of these polymers exhibit shear-thinning properties, i.e. the viscosity decreases with the shear rate. The apparent viscosity of the solutions was expressed with the Ostwald-de Waele relationship

$$
\mu_{\text {app }}=K \dot{\gamma}^{n-1}
$$

where $K$ is the consistency index $\left(\mathrm{Pas}^{\mathrm{n}}\right), n$ the flow index, and $\dot{\gamma}$ the average shear rate $\left(\mathrm{s}^{-1}\right)$. Rheological properties for the model fluids at varying concentrations are reported in Table 1. As discussed by Pérez et al. (2006), different correlations have been proposed to express the average shear rate inside a mixing tank. In this work, we used the empirical relationship found by Metzner and Otto due to its simplicity. The average shear rate was then expressed as $\dot{\gamma}=11.5 \mathrm{~N}$. A comparison with the relationship of Pérez et al. (2006) led to similar results. At higher polymer concentration - because of the appearance of viscoplastic effects - a more complex model would have to be used to express the apparent viscosity.

In their recent study, Gemello et al. (2018) investigated the effect of ethanol on bubble coalescence in water and showed that even at a very low concentration, the alcohol reduced the bubble size in the bubble column. To modify the coalescence of the system, ethanol at a concentration of $0.05 \%$ vol was dissolved in the tested solutions. Rheological characterization showed that at this concentration ethanol had no effect on the rheology of xanthan gum solutions. 
Table 1: Rheological indexes for xanthan gum and carboxymethyl cellulose for the different concentrations. Both of the polymers were provided by Sigma-Aldrich, USA.

\begin{tabular}{l|c|c|c|l}
\hline Fluid & Concentration $\%$ & $\mathrm{~K}\left(\mathrm{~Pa} \mathrm{~s}^{\mathrm{n}}\right)$ & $\mathrm{n}(-)$ & \multicolumn{1}{|c}{ Use } \\
\hline \multirow{2}{*}{ CMC } & 0.25 & 0.05 & 0.82 & Validation of CC \\
& 0.50 & 0.44 & 0.65 & \\
\hline \multirow{2}{*}{$\mathrm{XG}$} & 0.25 & 0.70 & 0.38 & Influence of \\
& 0.50 & 2.77 & 0.24 & rheology \\
\hline
\end{tabular}

\subsection{Bubble size measurement}

The Sauter mean diameter was obtained with a dual optical probe manufactured by A2 Photonic Sensor, France. It consists of two phase-detective glass probes vertically aligned, connected to an optoelectronic module. The acquisitions were done at $1 \mathrm{MHz}$. The characteristics of the probe were chosen based on the expected bubble size and gas fraction in the tank; the most important specification is the clearance $d$ between the two detective tips. In fact, the smallest detectable bubble diameter is equal to the tips gap. In Figure 2, the dual probe and its characteristic signal are shown. Once outside its protection cap, the diameter of the sensor's body was only $3 \mathrm{~mm}$, while the inter-probe distance was $d=730 \mu \mathrm{m}$.

The two probes simultaneously carry two signals, which can be crosscorrelated in terms of the Eulerian spatial correlation coefficient $R_{G}(d)$

$$
R_{G}(d)=\frac{\int_{t_{0}}^{t_{\exp }} S_{A}(t) S_{B}(t) d t}{\int_{t_{0}}^{t_{\exp }} S_{A}(t) d t}
$$

$S_{i}(t)$ is the instantaneous signals of the probe $i$ and $t_{\text {exp }}$ is the total time 

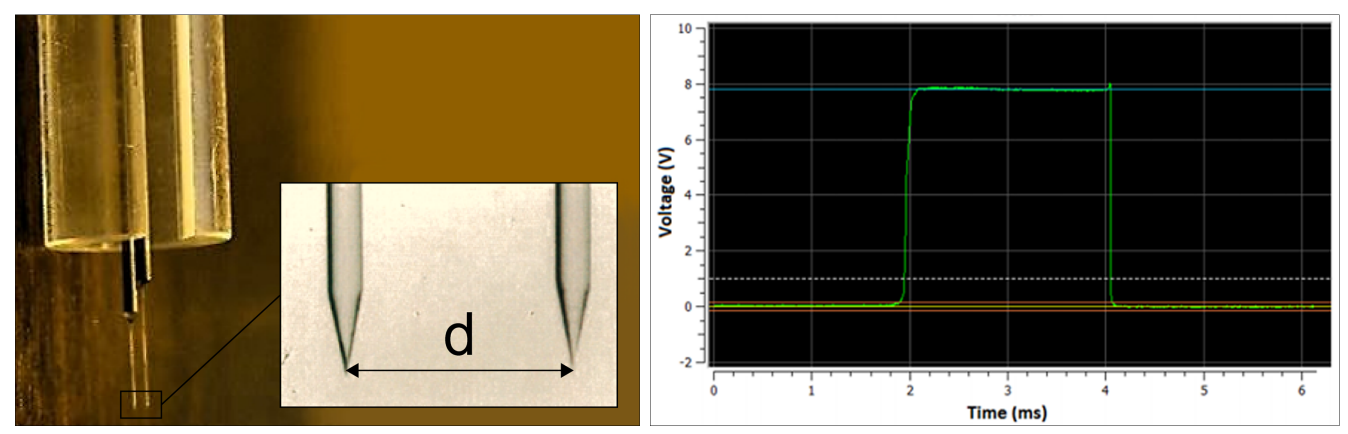

Figure 2: Detail of the optical probe and its plastic protection (left) and shape of the signal when a bubble is detected by the sensor (right).

of the measurements; the latter being long enough to ensure convergence, i.e. when at least 5000 bubbles were detected by the sensor. Raw signals were normalized in order to have $S_{i}(t)=0$ or 1 , depending on whether the probe's tip was in the liquid or in the gas phase respectively. Raimundo et al. (2016) derived a model for $R_{G}(d)$ by performing Monte Carlo simulations in which they considered different inter-probe distances, bubbles' shapes and their orientation respect to the sensor, finding a unique relationship between the cross-correlation coefficient and the ratio $d / d_{h, 32}$

$$
d_{h, 32}=a_{\text {shape }} \frac{d}{R_{G}(d)-1} \quad \pm 10 \%
$$

where $a_{\text {shape }}$ is a regression coefficient that depends on the bubble's shape. Raimundo et al. (2016) provided $a_{\text {shape }}=-1.4720$ for spherical bubbles and $a_{\text {shape }}=-1.5978$ in the case of oblate bubbles. Normally, in air-water systems, bubbles larger than $2 \mathrm{~mm}$ deviate from the spherical shape, the greater the size, the less spherical the shape of the bubble. At the operating conditions investigated, bubbles can be described as oblate spheroids; therefore, the horizontal diameter measured with the optical sensor (with 
$\left.a_{\text {shape }}=-1.5978\right)$ was converted using the following equation

$$
d_{32}=\sqrt[3]{d_{h, 32}^{2} d_{v, 32}}=\sqrt[3]{d_{h, 32}^{3} E}
$$

where $E$ is the bubble eccentricity. Eccentricity was calculated with the equation of Wellek et al. (1966), originally derived for liquid-liquid dispersion but validated also in gas dispersed systems (Clift et al. (2005))

$$
E=\left(1+0.163 E o^{0.757}\right)^{-1}
$$

where Eo is the Eötvös number.

The probe was inserted from an opening at the top of the tank in between two adjacent baffles. Due to geometrical constraints, it was not possible to move the probe along the radial direction, so the only accessible position was at a distance $\mathrm{T} / 3$ from the center of the tank (i.e. the location midway between the impeller blade tip and the vessel wall). The validity of using a single measurement to describe the distribution of mean bubble diameters is discussed in Section 3.3.1. To check the accuracy of the technique in stirred tanks and in non-Newtonian fluids, data obtained with the probe were compared to Sauter diameter calculated from photographic analysis at low gas fraction and in CMC solutions. Pictures were taken with a Nikon D300S placed $1 \mathrm{~m}$ away from the tank, and two LED panels were installed behind the vessel to enhance the visibility inside the liquid. The camera mounted a $105 \mathrm{~mm}$ lens with a focal ratio $f / 2.8$ and a shutter speed of $1 / 1600 \mathrm{~s}$ was used. Finally, the pictures were analyzed by an operator with the open source software ImageJ, and each bubble was considered as oblate ellipsoid, i.e. surface and volume were obtained by measuring major and minor axis. 
The Sauter mean diameter was then calculated from the surface and volume of every ellipsoid

$$
d_{32}=\frac{\sum_{i=1}^{400} V_{i}}{\sum_{i=1}^{400} A_{i}}
$$

where $S_{i}$ and $V_{i}$ are the surface and the volume of each bubble. For each condition, pictures were shot at different instants and convergence for $d_{32}$ was obtained by sampling 400 bubbles. An example of image used for the photographic analysis is represented in Figure 3. Frames had a resolution of about $4 \mathrm{~cm} \times 4 \mathrm{~cm}$ and were centered respect to the position of the optical probe. Results from image analysis also verified the assumptions on the bubbles' shapes, and average eccentricity in water and CMC was in the range 0.75-0.90, in agreement with Equation 6.

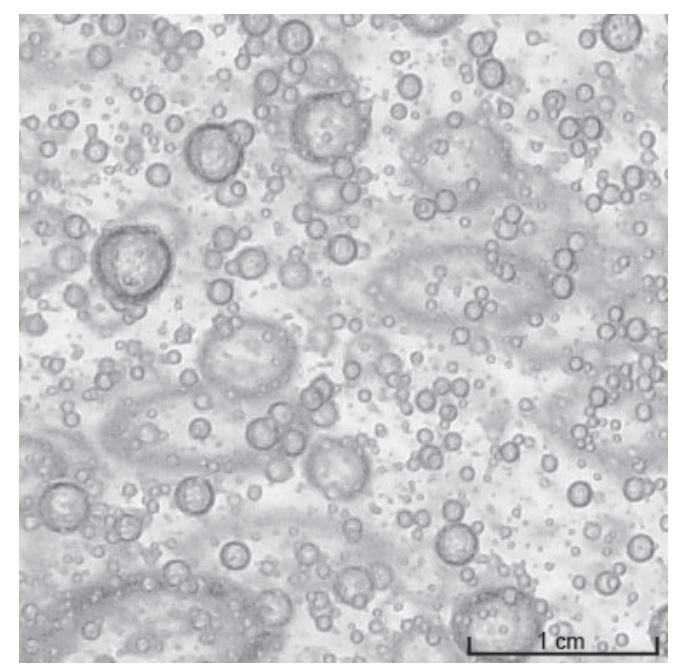

Figure 3: A frame acquired in a solution of CMC 0 50\%. Only bubbles with sharp outline were measured. 


\subsection{Gas holdup}

The global gas holdup was obtained visually by measuring the increase of liquid height due to the gas dispersed in the solution. The fraction of the gas volume is then defined as

$$
\alpha_{G}=1-\frac{H_{0}}{H_{G}}
$$

where $H_{0}$ is the initial height prior to inject air and $H_{G}$ is the average height of the free surface in the aerated system. The global gas holdup was also compared to the local gas fraction measured with the dual-probe in a larger tank (see Section 3.2) and integrated over the section of the tank.

\subsection{Volumetric mass transfer coefficient}

Clark-type oxygen probe (fast OX-100, manufactured by Unisense, Denmark) was used to measure the concentration of dissolved oxygen in the liquid. The probe was placed in the midplane between two adjacent baffles and in the impeller discharge region in order to minimize the influence of liquid film renewal at the probe tip, which can affect the reading especially in highly viscous media. The dynamic method was used to obtain the value of the volumetric mass transfer coefficient. The concentration curves were then analysed by considering the liquid as if perfectly mixed and the gas phase as if moving in a plug flow reactor (Gabelle et al. (2011)). The probe response time was measured in water and polymeric solutions, and it was found to be $<0.6 \mathrm{~s}$ which was also more than 5 times less than the characteristic transfer time $\left(1 / k_{L} a\right)$. Therefore, the probe dynamics was not taken into account (Al-Rubeai et al. (2015)). From a repeatability analysis, the precision of the

measure was assessed at 7\%. However, according to Pinelli et al. (2010), 
when the accuracy of the physical models was also considered, a minimum uncertainty of $20 \%$ had to be considered.

\section{Results and discussion}

\subsection{Validation of the optical probe measurement}

The cross-correlation technique was originally developed to measure average bubble diameter in bubble columns in the turbulent regime with a gas holdup of up to $40 \%$. However, in order to maintain the uncertainty of the measurement below 10\%, the global gas holdup should not be greater than $23 \%$. In our study, this condition was always respected, even at high gas velocity. Despite working with a lower gas content, the more chaotic gas flow pattern in a stirred tank, as well as the high viscosity of the model fluids, could affect the reliability of the technique. The outcome of the validation phase is presented in Figure 4, where it can be seen that the relative standard deviation (RSD) between the diameter obtained with the dual-probe and the diameter from the image analysis was about $11 \%$, regardless of the rheology of the liquid. The optical probe can also provide local values of the gas fraction. From the integration of these values over the volume of the liquid, the global gas holdup could be obtained. This measurement was done

in a large vessel, and the comparison with the global gas holdup obtained with the visual method led to a RSD of less than $9 \%$.

These findings suggest that the accuracy of the optical probe technique is neither affected by the viscosity of the fluid nor by hydrodynamics of the mixing tank. Moreover, it is reasonable to also extend the results obtained in $\mathrm{CMC}$ to $\mathrm{XG}$ solutions, because the two polymeric solutions have similar 
viscosity under the operating conditions investigated in the validation study. Besides, this proved that the volume fraction of bubble smaller that the distance between probes keeps small enough to not impact the calculation of $d_{32}$. This result is coherent with Gabelle et al. (2011), who found that the volume fraction of small trapped bubble in CMC and XG solutions was lower $04 \%$.

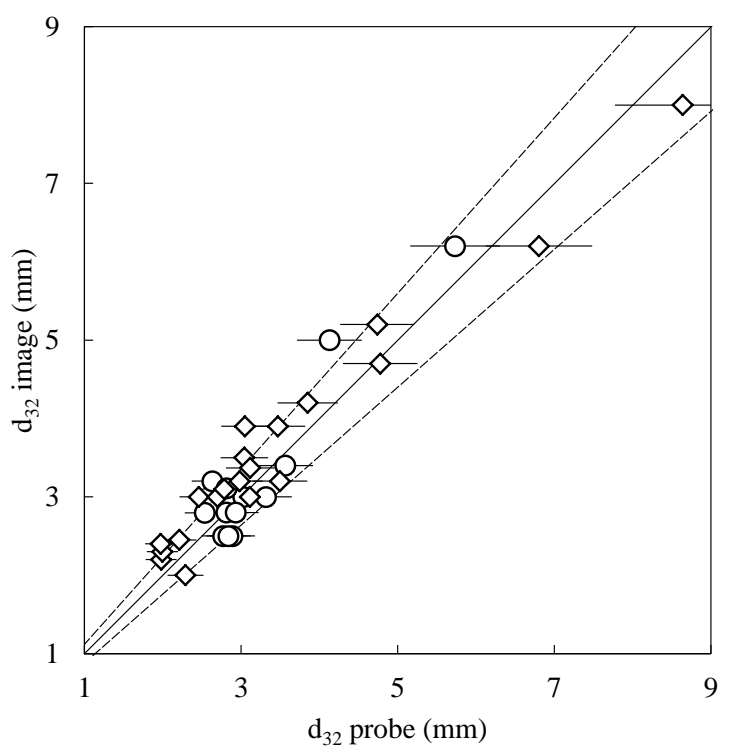

Figure 4: Mean Sauter diameter measured with the optical probe and from image analysis. Data refers to: $(\mathrm{O})$ water and $(\diamond) \mathrm{CMC} 0.25 \%$ and $0.50 \%,(--) \pm 12 \%,(-)$ parity line.

\subsection{Spatial distribution of gas holdup and bubble size and effect of tank size}

Firstly, the spatial distribution of the local Sauter mean diameter and gas holdup were addressed. During this phase of the study, the optical probe was inserted inside a larger tank in which more locations were accessible for measurement. This tank had a diameter $T=0.6 \mathrm{~m}$, and it was geometri- 
cally similar to the tank described in Section 2. Figure 5 shows the spatial distribution of the Sauter mean diameter measured in the large tank at two different gas flow rates. Outside the impeller discharge zone, the Sauter mean diameter was almost constant, in accordance with what had been found by other researchers (Barigou and Greaves (1992), Bombač et al. (1997), Alves et al. (2002)). A slightly increase of the bubble size with the liquid height could be noticed. Nevertheless, the standard deviation of the diameters was less than 7\%; hence, the definition of a bulk diameter to represent the entire gas phase seems to be valid. The region close to the impeller is not the main focus of this study, so it was decided to not investigate it further in order to avoid an excessive tearing of the optical probe. Measurements made in both tanks at constant dissipated power and superficial gas velocity showed that $d_{32}$ was practically the same for both vessel sizes. Consequently, the majority of experiments were done in the small tank (Figure 1) which allowed us to investigate a wider range of gas velocities and dissipated power. In this configuration, the value at the center of the liquid and between the blades and the wall was used as the representative Sauter mean diameter.

\subsection{Effect of the rheology and additives on bubble size and mass transfer}

The correlations presented in this work are based on the following formalism widely used in similar studies to describe the volumetric mass transfer coefficient, the gas holdup, and the bubble size (Linek et al. (2004), GarciaOchoa and Gomez (2009), Gabelle et al. (2011), Bach et al. (2017))

$$
X\left(=d_{32}, \alpha_{G}, k_{L} a, k_{L}\right)=c_{1}\left(\frac{P_{G}}{V}\right)^{c_{2}} U_{G}^{c_{3}} \mu_{a}^{c_{4}}
$$

The regression coefficients $c_{i}$ were obtained with the method of least squares. 


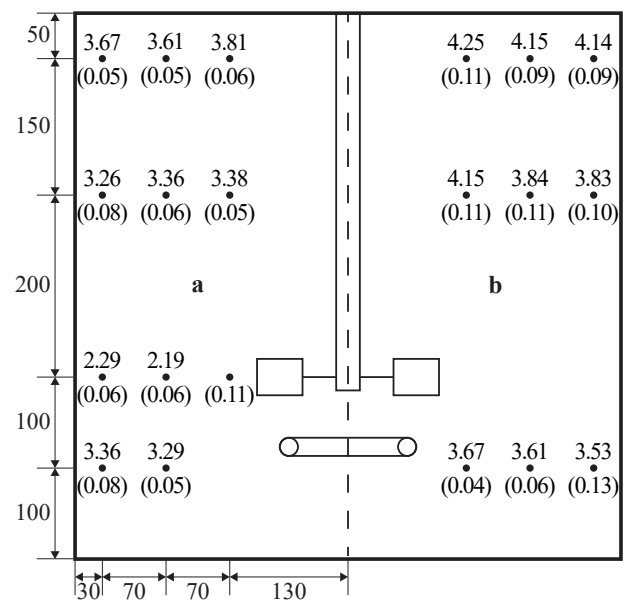

Figure 5: Sauter mean diameter in $\mathrm{mm}$ and gas holdup (in brackets) in the large tank. Data were collected for $N=8.3 \mathrm{~s}^{-1}$ and for $U_{G}=8 \mathrm{~mm} \mathrm{~s}^{-1}$ (a) and $U_{G}=20 \mathrm{~mm} \mathrm{~s}^{-1}$ (b). The probe locations are also indicated.

\subsubsection{Sauter mean diameter}

The Sauter mean diameter for the studied fluids is presented in Figure 6. Regardless of the rheology of the liquid, the average bubble size decreased when the power input increased, while it increased with the air flow rate. For a fixed superficial gas velocity, more energy is provided to the liquid by increasing the impeller rotation speed, so breakage phenomena are promoted. The effect of the gas flow rate, on the other hand, is specular. In fact, when more gas enters the system, gas cavities behind the Rushton blades change shape and become bigger, directly affecting the energy transferred by the impeller (Paul et al. (2004)). In addition to this phenomenon, bubbles' coalescence is favoured at higher gas concentration. This effect explains the increase in bubble size at constant dissipated power for different gas velocities. From the results obtained in demineralized and in tap water, it 


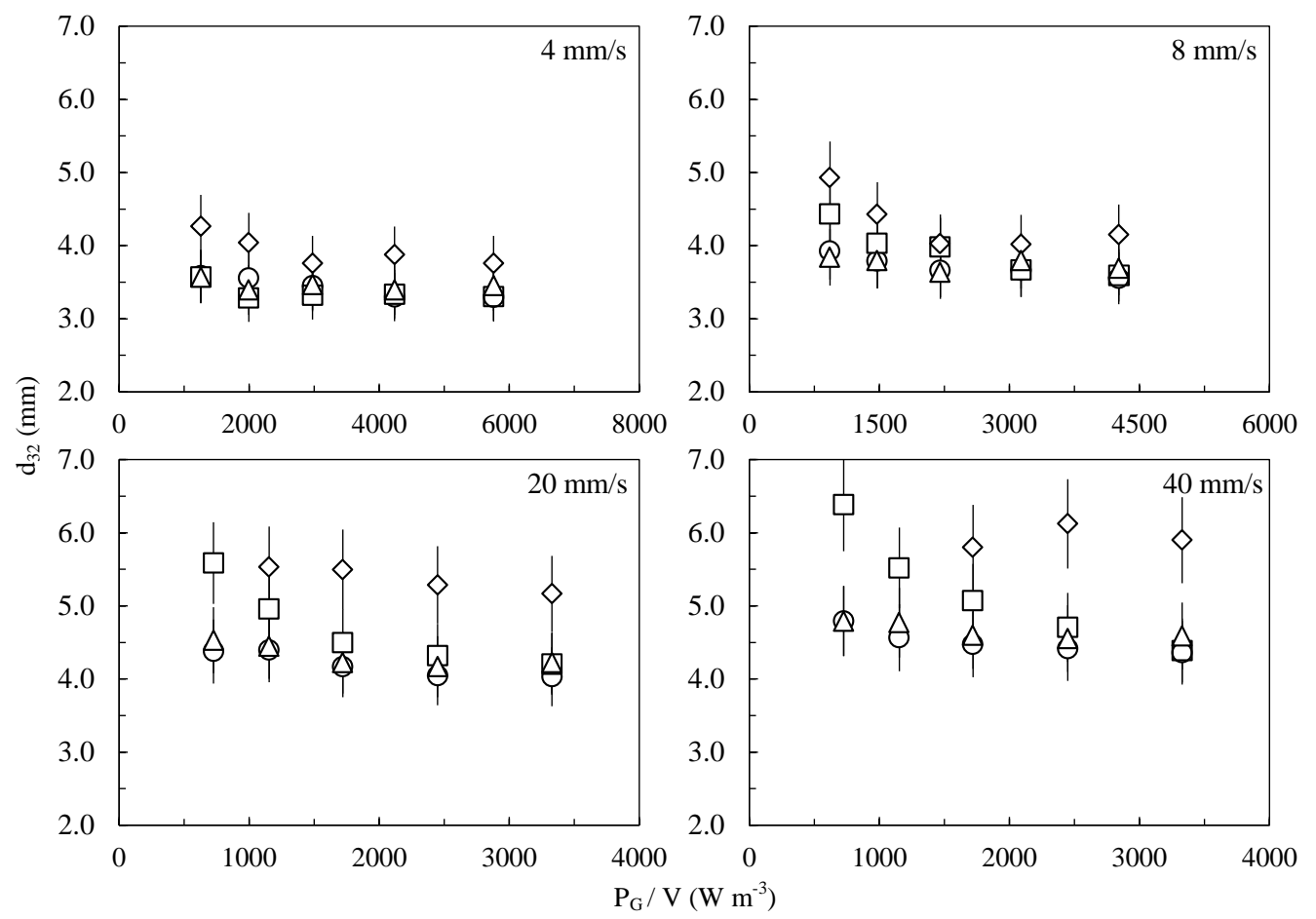

Figure 6: Sauter mean diameter at several superficial gas velocities in: (O) tap water, $(\Delta)$ demineralized water, ( $\square$ ) XG $0.25 \%$ and $(\diamond)$ XG $0.50 \%$.

is clear that the effect of contaminants in tap water was overshadowed by the influence of gas flow rate and dissipated power. The concentration of the polymer had a major effect, especially at relatively low impeller speed and high gas flow rate. For example, at $U_{G}=4 \mathrm{~mm} \mathrm{~s}^{-1}$, gas dispersion in XG $025 \%$ was characterized by the same average diameter as measured in water, while at higher gas velocity, bigger bubbles were measured in the polymeric solution. Only at the maximum rotation speed, the Sauter mean diameter approached the values in water. In the solution XG $050 \%$, the measured bubble diameter was always higher $(+22 \%$ on average) than the one measured in water at the same conditions even at the maximum impeller 
speed.

Due to the presence of surfactants and additives, the surface tension of the fermentation broth is different from water and polymeric solutions. The surface tension in the filtered broth was found to be $0.032 \mathrm{~N} \mathrm{~m}^{-1}$; additionally, xanthan gum did not have any effect on the surface tension. As a consequence, the coalescence mechanisms are drastically affected and the bubble size is expected to be smaller. Measurements with the optical probe confirmed this assumption (Figure 7).

Visually, the gas inside the filtered broth was finely dispersed in the liquid

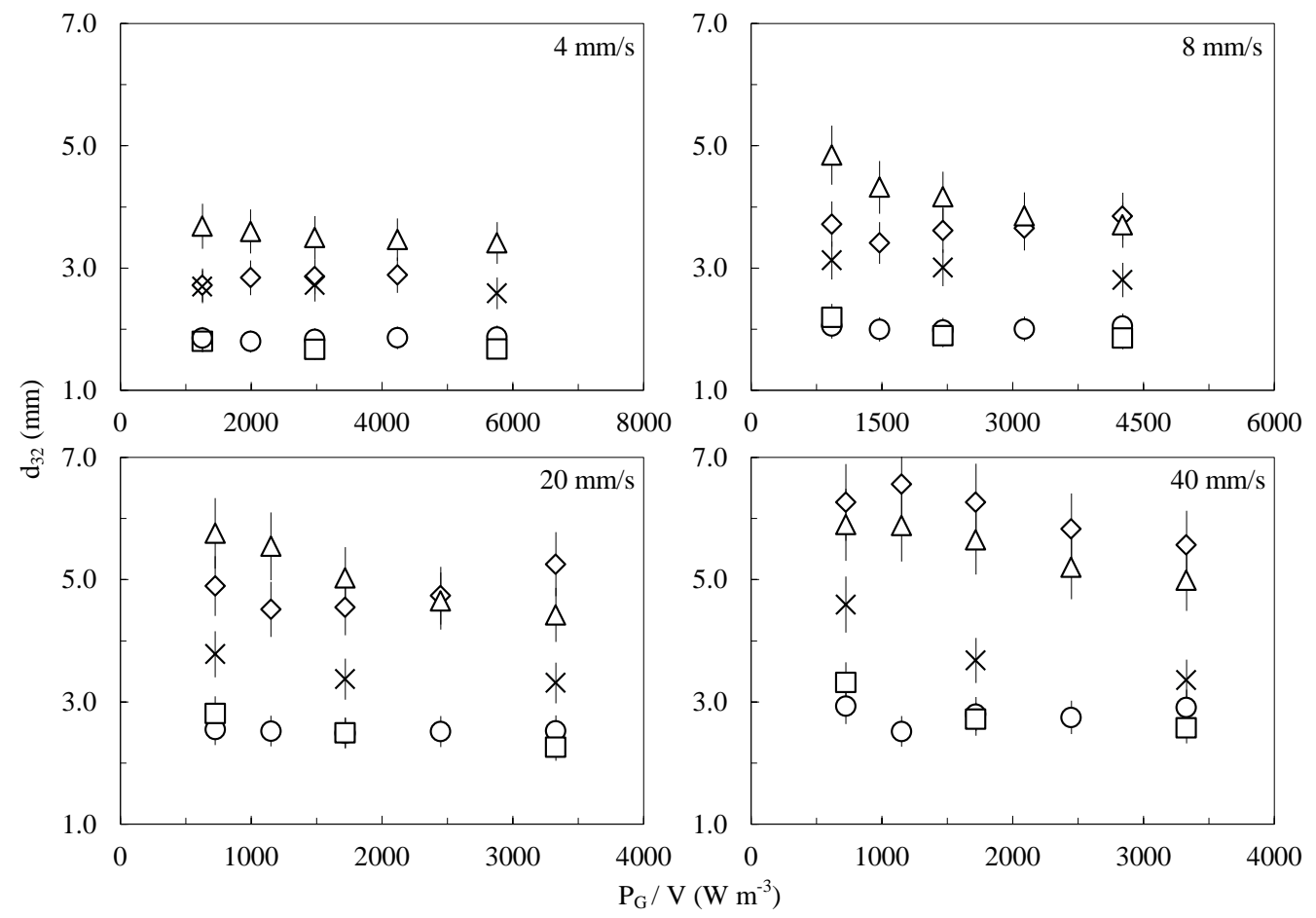

Figure 7: Effect of additives on the bubble Sauter mean diameter. Data collected at several superficial gas velocities in: (O) broth, ( $\square$ ) water + ethanol, $(\diamond)$ broth + XG 0.50\%, $(\triangle)$ XG $0.50 \%$ + ethanol and (×) XG $0.25 \%+$ ethanol. 
phase with micro-bubbles smaller than the distance between the glass tips of the probe, so they could not be detected. However, the Sauter mean diameter, by definition, should not be affected excessively because of the greater contribution of the bigger bubbles. For the biological media (i.e. filtered broth and filtered broth + XG 0 50\%), the effect of the dissipated power was almost negligible. Some influence of power input could be noticed only at $U_{G}=40 \mathrm{~mm} \mathrm{~s}^{-1}$ for both of the systems. In the filtered broth, bubble diameter was in the range $1.5-2.6 \mathrm{~mm}$, where the bigger bubbles were measured at a high gas flow rate. The same bubble size range was measured in water after the addition of pure ethanol. In fact, the bubble size measured in solutions with ethanol was found to be smaller, as already reported by other authors (Machon et al. (1997), Gemello et al. (2018)).

With a concentration of alcohol of $005 \%$ vol, a reduction of the average diameter of around $50 \%$ was measured in water, while in xanthan gum solutions the reduction was less significant. In XG $025 \%$ and XG $050 \%$, the bubble diameter decreased after the dissolution of ethanol, on average, by $25 \%$ and $5 \%$ respectively. This results indicates that both additives and viscosity affected the mean bubble size, but the latter had a greater impact on the measured $d_{32}$. After adding ethanol, the relative difference between the bubble diameter measured in XG 0 50\% and in filtered broth + XG 0 50\% was only si6\%. By adding ethanol, it was possible to modify the coalescence of air bubbles, thus reducing the bubble size. However, the effect of ethanol on the bubble surface phenomena is not easy to predict. Machon et al. (1997) studied the effect of electrolytes and alcohols on bubble diameter, concluding that the size of the bubbles cannot be simply correlated to the surface ten- 
sion of the solution. In fact, at the alcohol concentration used in this study, the surface tension of the solution can be considered constant (Vazquez et al. (1995), Gemello et al. (2018)).

Figure 8 shows the comparison between the correlation proposed in this study and others available in the literature. Alves et al. (2002) correlated their data only in terms of dissipated power and only in non-viscous solutions. Furthermore, they investigated superficial gas velocities of up to $5 \mathrm{~mm} \mathrm{~s}^{-1}$. Even though the influence of the power dissipated was almost the same, their correlation was not able to predict the experimental data of this work, with an average error of about $30 \%$. Among the few correlations where the viscosity is considered, the correlation proposed by Bhavaraju et al. (1978)

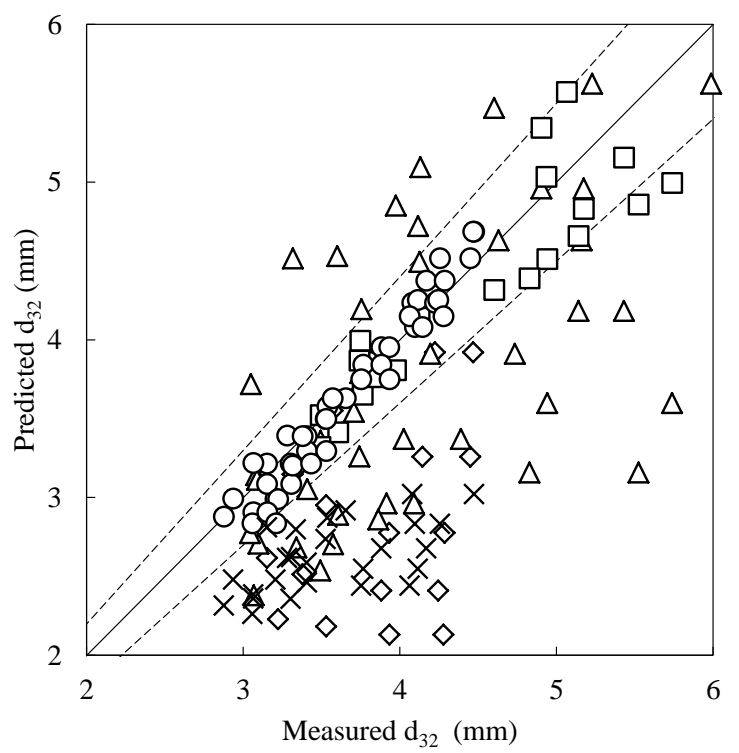

Figure 8: Comparison between different correlations to measure the mean bubble size. This work: (০) water, (口) XG. Bhavaraju et al. (1978): $(\diamond)$ water, $(\triangle)$ XG. Alves et al. (2002): (×) water. $(--) \pm 10 \%,(-)$ parity line. 
led to a similar error (26\%). They derived their equation from theoretical considerations, so the dissipated power is present with the power -0.4 . The correlation proposed in this work (Equation 9, Table 2) predicted the experimental data with an RSD of $7 \%$. The scatter of the points with other authors' correlations is not surprising because of the different operating conditions investigated (gas flow rate, gas sparger technology).

The diameter measurements performed in CMC 0 5\% solutions have been also compared with predictions from Equation 9, and an error below $13 \%$ was found. Therefore, CMC and XG solutions exhibits similar behaviours, so the measurement method is as well adapted to one system as to the other.

\subsubsection{Gas holdup}

The global gas holdup in water and xanthan gum solutions at different gas velocities is represented in Figure 9. By increasing the impeller speed and the power dissipated, more bubbles were "trapped" in the recirculation flow. This caused an increase in the global gas holdup regardless of the liquid studied. The same outcome was found by increasing the air flow rate, because of the greater volume of gas dispersed in the liquid phase. As previously discussed, air bubbles are bigger in polymeric solutions where their rise velocity is higher, explaining the lower holdups compared to water. It was only for

$U_{G}=40 \mathrm{mms}^{-1}$ that some differences between tap water and demineralized water were recorded, probably because of the greater importance of bubble coalescence at high gas flow rate, where the presence of contaminants in water has a more important effect. Regression coefficients for Equation 9 are listed in Table 2 together with the relative error.

Measurements in the fermentation broth (Figure 10) showed a consider- 
able increase in the gas holdup, consistent with the results on bubble size discussed previously. As expected, adding ethanol to water and polymeric solutions had the same effect, with an average increase in the holdup by $13 \%$. Even though the addition of ethanol into water led to similar values of the Sauter mean diameter in the broth, the gas holdup data were notably different. This outcome could be explained by the presence of micro-bubbles in the fermentation media where they constitute an important fraction of the gas phase, and thereby causing an increase in the gas holdup. The volume of gas retained in the filtered broth with XG $0.50 \%$ was about $30 \%$ higher than

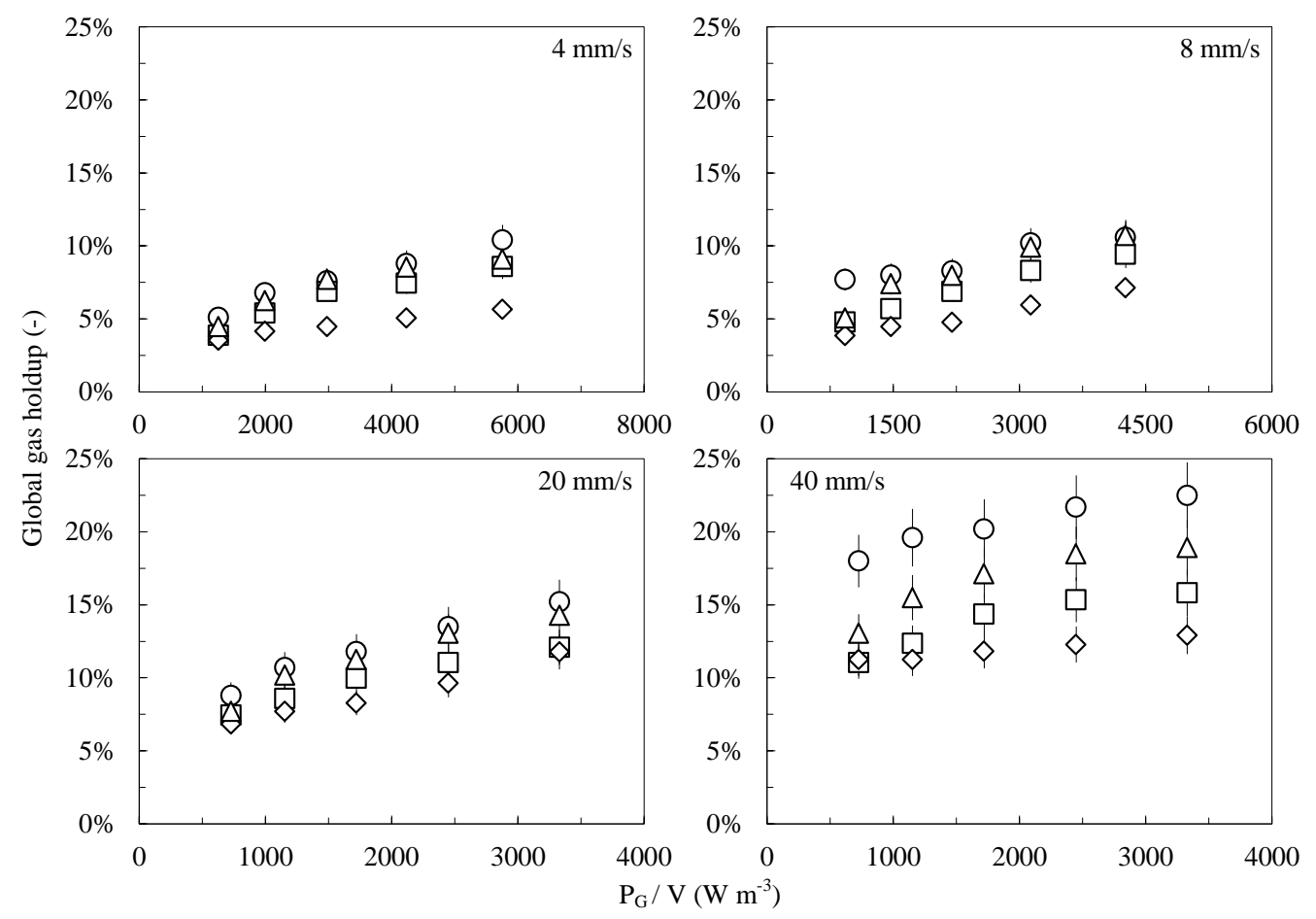

Figure 9: Global gas holdup at different superficial gas velocities measured in: (O) tap water, $(\triangle)$ demineralized water, $(\square)$ XG $0.25 \%$ and $(\diamond)$ XG $0.50 \%$. 
the values obtained in XG $0.50 \%$ aqueous solutions. However, by adding ethanol it was possible to reduce this difference to $15 \%$.

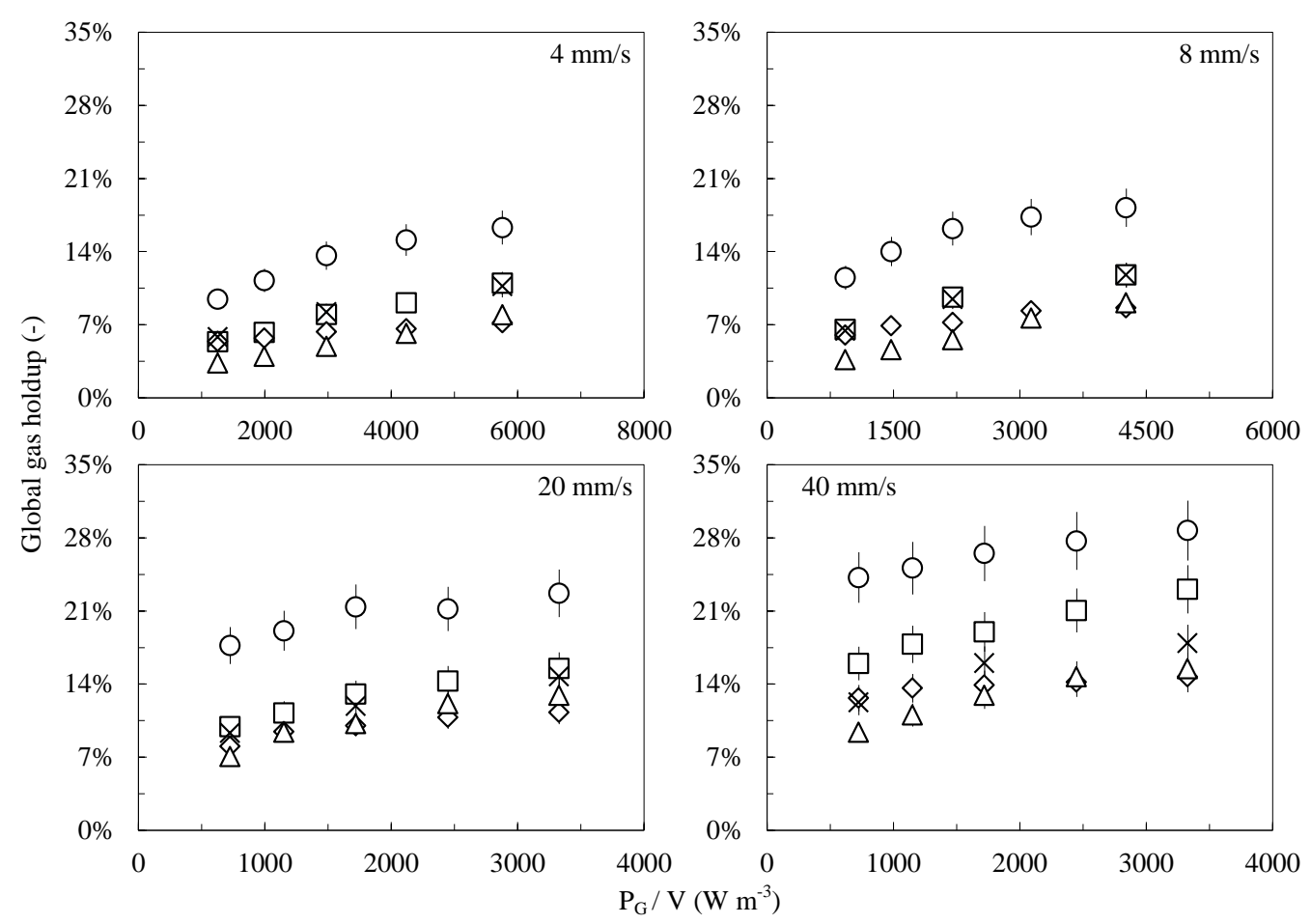

Figure 10: Global gas holdup at different superficial gas velocities in: (O) broth, (ם) water + ethanol, $(\diamond)$ broth + XG $0.50 \%,(\triangle)$ XG $0.50 \%+$ ethanol, and $(\times)$ XG $0.25 \%$ + ethanol.

\subsubsection{Volumetric mass transfer coefficient}

The findings that have been presented so far point to the conclusion that rheology and contaminants drastically modify the interfacial area. Consequently, they have a certain influence on the mass transfer phenomena. It is widely known that viscosity negatively effects the volumetric mass transfer coefficient in agitated reactors (Garcia-Ochoa and Gomez (2009), Gabelle 
et al. (2012)). In Figure 11, $k_{L} a$ values are reported for all the media analysed except for the filtered broth. In fact, as stated previously, a considerable fraction of gas consists of bubbles smaller than $0.5 \mathrm{~mm}$. It has been reported that under these conditions, the dynamic method to estimate the mass transfer coefficient does not provide reliable results (Pinelli et al. (2010)). Small bubbles give a different contribution to the $k_{L} a$, so different techniques and models have to be used in this case. Compared to water, a loss of $64 \%$

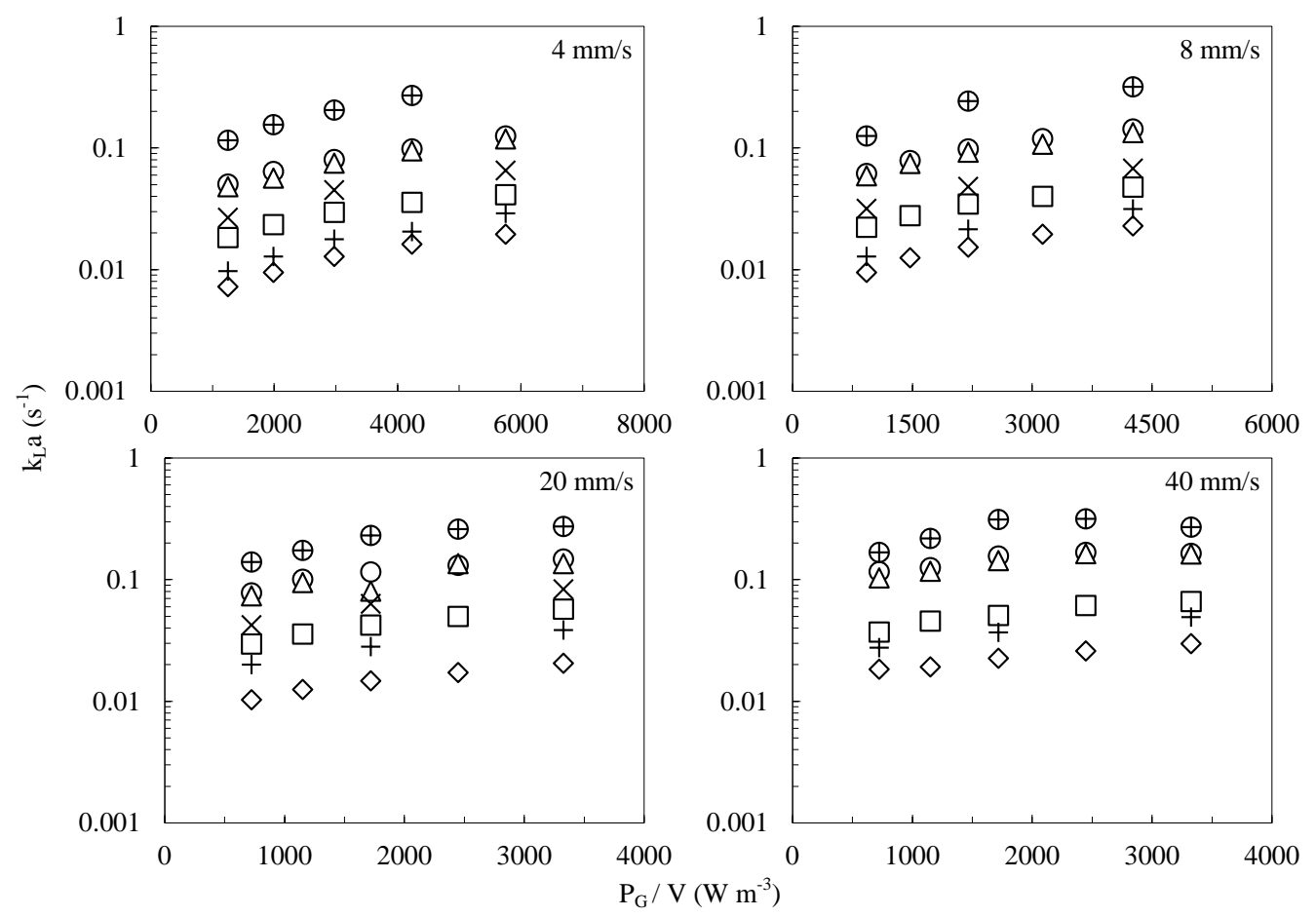

Figure 11: Influence of dissipated power and gas flow rate on the volumetric mass transfer coefficient. Data obtained in: $(O)$ tap water, $(\Delta)$ demineralized water, $(\oplus)$ water + ethanol, () XG $0.25 \%,(\times)$ XG $0.25 \%+$ ethanol, $(\diamond)$ XG $0.50 \%$ and $(+)$ XG $0.50 \%+$ ethanol.

and $85 \%$ was found for XG $0.25 \%$ and XG $0.50 \%$ respectively. If there was 
any difference between demineralized water and tap water, it was less than the measurement error. The regression coefficients (Table 2) were found to be in agreement with the values that are normally encountered in literature (Van't Riet (1979), Garcia-Ochoa and Gomez (2009), Gabelle et al. (2011)).

The $k_{L} a$ increased after adding ethanol, the magnitude of its effect depending on the rheology of the liquid. In the case of water, a two-fold increase was observed, while in XG the effect of the ethanol was dampened by the viscosity, and $k_{L} a$ values were $50 \%$ higher than the ones measured in $\mathrm{XG}$ solutions without ethanol.

\subsubsection{Liquid-side mass transfer coefficient}

In regard to the results presented in Section 3.2, it is reasonable to define an average $k_{L}$ from the measurement of Sauter mean diameter, gas holdup and volumetric mass transfer coefficient:

$$
k_{L}=k_{L} a\left(\frac{6}{d_{32}} \frac{\alpha_{g}}{1-\alpha_{g}}\right)^{-1}
$$

Values of $k_{L}$ for fluids at different rheology are reported in Figure 12. The average $k_{L}$ in water was twice the value in XG $0.25 \%$ and more than three times that of the one in XG $0.50 \%$, confirming that the rheology of the system has an important effect on the mass transfer at the gas-liquid interface. By taking into consideration the results discussed in Section 3.3.3, it can be deduced that viscosity hinders the mass transfer because it negatively affects both the interfacial area and $k_{L}$. It is important to mention that at the concentration of xanthan gum used in this study, the oxygen diffusion coefficient $\left(\mathcal{D}_{L}\right)$ is the same as in water (Ho et al. (1988)); therefore, if Danckwerts's theory is used to describe the mass transfer mechanism, one could assume that 

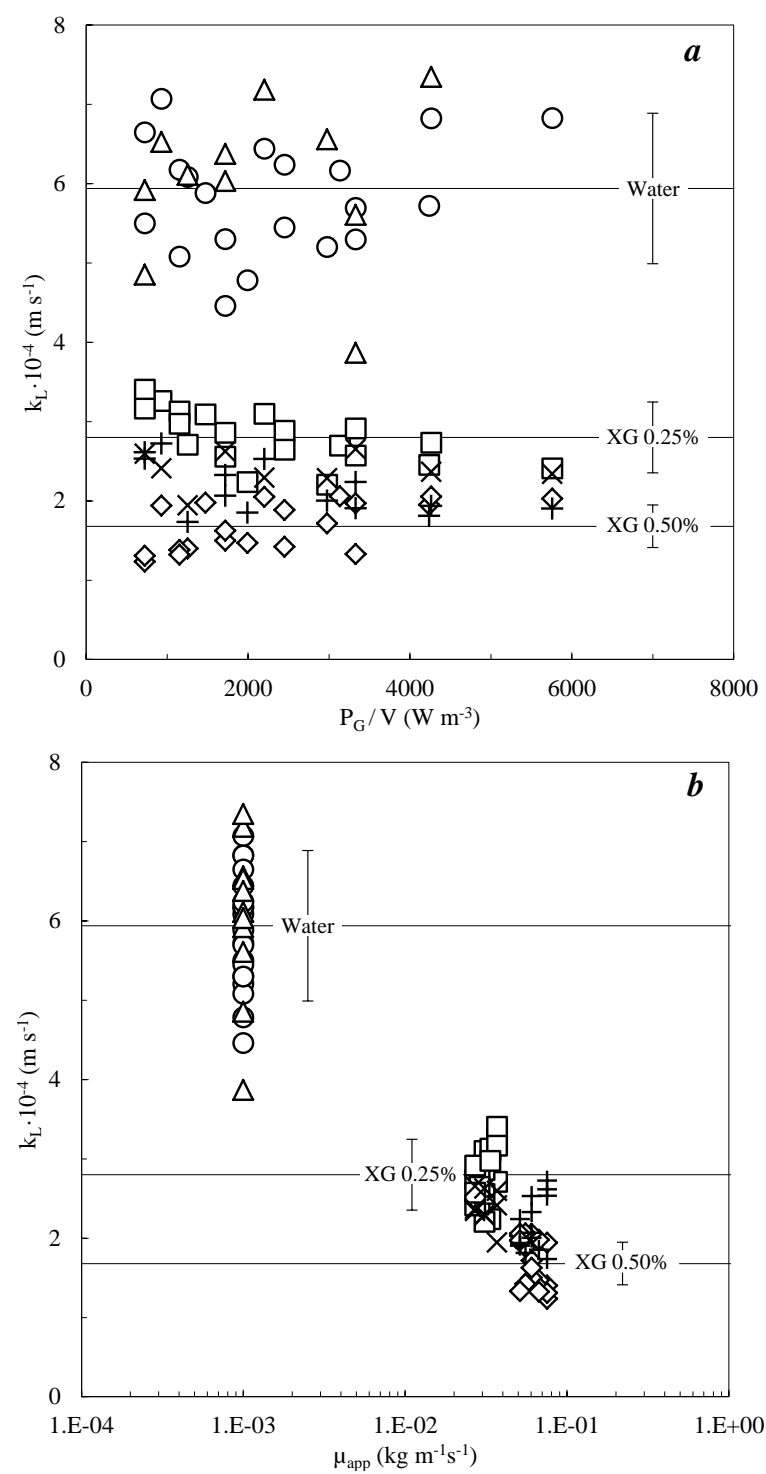

Figure 12: Liquid-side mass transfer coefficient as a function of the dissipated power (a) and the apparent viscosity (b). Data obtained in: $(O)$ water, $(\triangle)$ water + ethanol, $(\square)$ XG $0.25 \%,(\times)$ XG $0.25 \%$ + ethanol, $(\diamond)$ XG $0.50 \%$ and $(+)$ XG $0.50 \%+$ ethanol. For every fluid, error bars $( \pm 16 \%)$ around the mean value are also reported. 
rheology influences the surface renewal rate at the bubble's interface (Danckwerts (1951), Garcia-Ochoa and Gomez (2009)). After adding ethanol, no variations of the $k_{L}$ values were noticed in water. As a consequence, the increase of $k_{L} a$ due to the addition of ethanol in the solutions (Figure 11) is linked only to the modification of interfacial area. Addition of ethanol in XG $025 \%$ and $050 \%$ led to opposite effects on the average $k_{L}:-15 \%$ and $+19 \%$ respectively. These apparently contradictory outcomes were considered to be only the result of the inaccuracy of calculation, as they stand close to the associated standard error. Moreover, contrary to most of the findings available in the literature, neither any effect of the dissipated power, nor any of the gas flow rate was observed (Table 2).

Equation 9 for $k_{L}$ can be rewritten in the following form:

$$
k_{L}=2.56 \cdot 10^{-3}\left(\frac{\rho \mathcal{D}_{L}}{\mu_{\text {app }}}\right)^{0.25}
$$

The liquid density and the diffusion coefficient were added only to obtain a dimensionless correlation, but for all of the systems studied their values were considered to be, in fact, constant. Figure 13 shows the comparison between Equation 11 and experimental results for $U_{G}=8 \mathrm{mms}^{-1}$; the two correlations from the literature that exhibited the best agreement are also reported. Most of the correlations proposed in other studies are based on Kolmogorov's theory of isotropic turbulence, and they have the following general formula:

$$
k_{L}=C \sqrt{\frac{\mathcal{D}_{L}}{\nu}}\left(\frac{P_{G}}{\rho V} \nu\right)^{1 / 4}
$$

Several values of $C$ can be found in the literature ranging from 0.3 to 1.13 (Lamont and Scott (1970), Prasher and Wills (1973), Kawase et al. (1987), 
Table 2: Regression coefficients for Equation 9 proposed in this work.

\begin{tabular}{|c|c|c|c|c|c|c|}
\hline & system & $\mathrm{c}_{1}$ & $\mathrm{c}_{2}$ & $\mathrm{c}_{3}$ & $\mathrm{c}_{4}$ & $\mathrm{RSD} \%$ \\
\hline \multirow{3}{*}{$d_{32} \mathrm{~m}$} & $\mathrm{~W}, \mathrm{XG}$ & $1.76 \cdot 10^{-2}$ & -0.08 & 0.15 & 0.04 & 6.6 \\
\hline & $\mathrm{W}+\mathrm{EtOH}, \mathrm{XG}+\mathrm{EtOH}$ & $2.88 \cdot 10^{-2}$ & -0.08 & 0.17 & 0.17 & 11.6 \\
\hline & $\mathrm{B}, \mathrm{B}_{\mathrm{XG}}$ & $2.41 \cdot 10^{-2}$ & - & 0.30 & 0.16 & 7.5 \\
\hline \multirow{3}{*}{$\alpha_{G}(-)$} & $\mathrm{W}, \mathrm{XG}$ & $4.68 \cdot 10^{-2}$ & 0.30 & 0.45 & -0.07 & 10.8 \\
\hline & $\mathrm{W}+\mathrm{EtOH}, \mathrm{XG}+\mathrm{EtOH}$ & $4.20 \cdot 10^{-2}$ & 0.32 & 0.44 & -0.07 & 10.8 \\
\hline & $\mathrm{B}, \mathrm{B}_{\mathrm{XG}}$ & $7.50 \cdot 10^{-2}$ & 0.17 & 0.35 & -0.16 & 5.8 \\
\hline \multirow{2}{*}{$k_{L} a\left(\mathrm{~s}^{-1}\right)$} & $\mathrm{W}, \mathrm{XG}$ & $1.54 \cdot 10^{-3}$ & 0.41 & 0.31 & -0.36 & 14.4 \\
\hline & $\mathrm{W}+\mathrm{EtOH}, \mathrm{XG}+\mathrm{EtOH}$ & $5.86 \cdot 10^{-4}$ & 0.45 & 0.18 & -0.48 & 17.7 \\
\hline$k_{L}\left(\mathrm{~m} \mathrm{~s}^{-1}\right)$ & $\begin{array}{l}\mathrm{W}, \mathrm{XG} \\
\mathrm{W}+\mathrm{EtOH}, \mathrm{XG}+\mathrm{EtOH}\end{array}$ & $1.01 \cdot 10^{-4}$ & - & - & -0.25 & 16.6 \\
\hline
\end{tabular}

$\mathrm{W}=$ water, $\mathrm{XG}=$ xanthan gum, $\mathrm{B}=$ filtered broth, $\mathrm{B}_{\mathrm{XG}}=$ filtered broth with xanthan gum $0.50 \%_{\mathrm{w}}, \mathrm{EtOH}=$ ethanol at a concentration of $0.05 \%$ vol .

Kawase et al. (1992), Zhang and Thomas (1995), Linek et al. (2005)). Attempts were made by Kawase et al. (1992) to find the proportionality constant from physical parameters. From the analysis of hydrodynamics, they derived the following equation:

$$
k_{L}=C^{\prime}(n, K) \sqrt{\mathcal{D}_{L}}\left(\frac{P_{G}}{V} \frac{1}{K}\right)^{1 / 2(1+n)}
$$

where coefficient $C^{\prime}$ is a function of the rheological index. For water, the authors provided a value of $C^{\prime}=0.301 ; C^{\prime}$ values for model fluids were obtained from fitting of experimental data. In general, their correlation was able to 

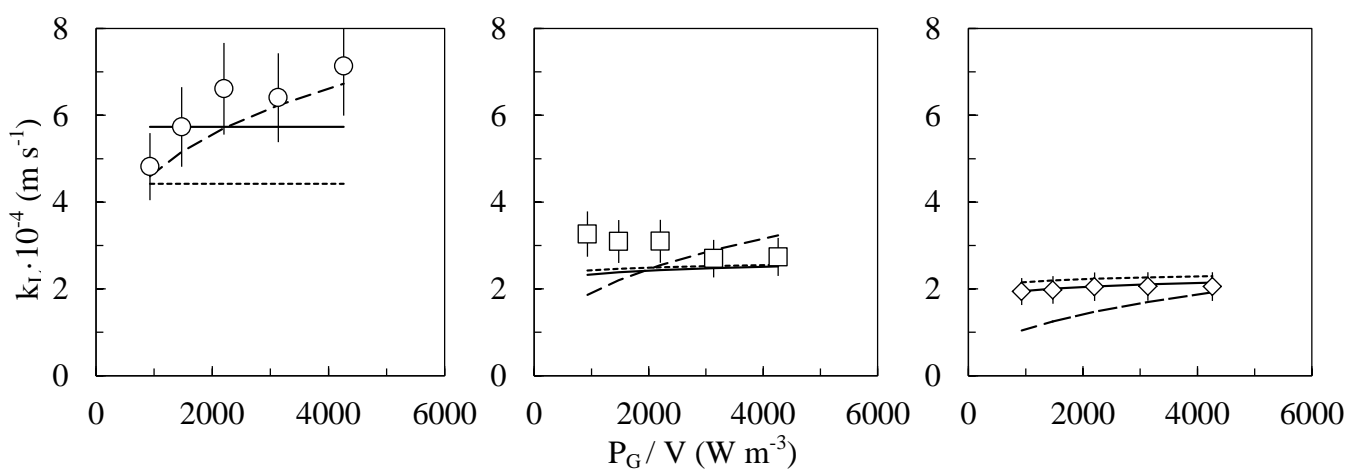

Figure 13: Liquid-side mass transfer coefficient for $U_{G}=8 \mathrm{~mm} \mathrm{~s}^{-1}$ and predicted values.

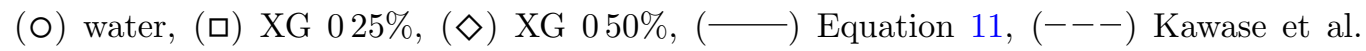
1991, (---) Calderbank and Moo-Young 1961.

predict data from this work within an error of $23 \%$. In both of Equation 11 and Equation 13, the viscosity of the liquid phase appears with the same exponent. The correlation of Kawase et al. (1992) shows the dependency of dissipated power with an exponent equal to 0.25 for water and $0.36-0.40$ for model fluids.

However, Equation 11 - and more generally the fact that power supply does not explicitly affect $k_{L}$ - agrees with other correlations from the literature. For example, the correlation proposed by Calderbank and Moo-Young (1961) expresses a liquid-side mass transfer coefficient that depends neither on the bubble slip velocity nor on the dissipated power, but only on physical properties:

$$
k_{L}=0.42\left(\frac{\Delta \rho \nu g}{\rho_{L}}\right)^{1 / 3}\left(\frac{\mathcal{D}_{L}}{\nu}\right)^{1 / 2}
$$

This relationship depends on the viscosity of the phases, and it is valid for bubbles larger than $2.5 \mathrm{~mm}$. Prediction of our data with Equation 14 led to an average error of $24 \%$. In Figure 14 the totality of the experimental 
values of $k_{L}$ are compared with the correlations afore discussed. The total uncertainty of liquid-side mass transfer coefficient was estimated from the error of the experimental techniques used throughout the study and it was found to be around $16 \%$. However, if the maximum error relative to $k_{L} a$ data is considered (i.e. 20\%, Pinelli et al. (2010)), the uncertainty of $k_{L}$ rises to $24 \%$ that is comparable to the average error of the correlation proposed. It was therefore difficult to precisely quantify the effect of input power on the mass transfer rate.

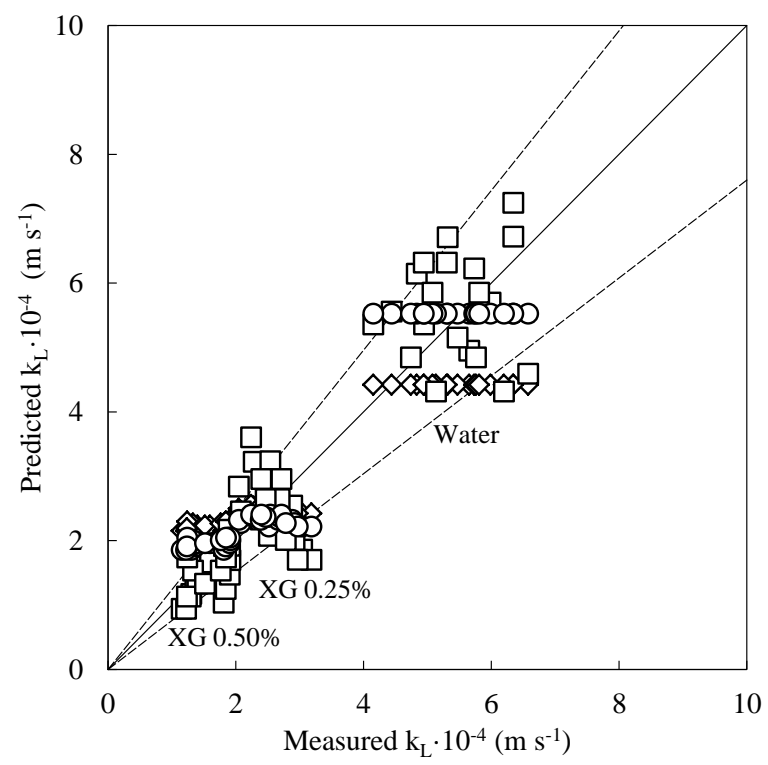

Figure 14: Comparison between different correlations to estimate the oxygen transfer rate. (০) This work, ( $\square)$ Kawase et al. 1991, ( $\diamond)$ Calderbank and Moo-Young 1961, $(--) \pm 10 \%,(-)$ parity line.

Beyond the choice of the correlation to estimate $k_{L}$, one important question that arose was the definition of average shear rate to calculate the apparent viscosity in the tank (Equation 2). In the present study, the Metzner- 
Otto's model was considered, but other calculations can be found in the literature, as reported by Pérez et al. (2006). According to Pérez and colleagues, average shear rate in turbulent non-Newtonian fluids depends on rheological indexes, so that $\dot{\gamma}=\left(\frac{1}{K} \frac{P_{G}}{V}\right)^{1 /(n+1)}$. Alternatively, considering that the shear rate in the vicinity of bubbles is governed by the slip between gas and liquid would lead to $\dot{\gamma} \approx \frac{U_{G} / \alpha_{G}}{d_{32}}$ (Amirnia et al. (2013)). However, when these alternative definitions of the average shear rate were used to estimate the apparent viscosity, very similar regression coefficients were obtained for Equation 9: coefficient $c_{1}$ was found to be equal to $9.94 \cdot 10^{-5}$ and $1.03 \cdot 10^{-4}$ respectively, while $c_{4}$ remained equal to -0.25 , and the standard errors were comparable.

In conclusion, in this study it was found that viscosity has a primary role in the mass transfer in stirred tanks, affecting mainly the mass transfer rate. Gas flow rate and impeller rotation speed influenced the measured $k_{L} a$ as well, but their effect was due to modification of the interfacial area only. In particular, the dissipated power had a negligible effect on the liquid-side mass transfer rate; however, because of the accuracy of $k_{L}$ data, the influence of power input could have been underestimated.

\section{Conclusions}

An innovative technique was validated to estimate bubble size in turbulent systems based on a dual optical probe and then used in a stirred tank reactor. Gas holdup and volumetric mass transfer coefficient were measured as well. The experiments were done in water, in non-Newtonian shear-thinning solutions of xanthan gum, and in a filtered broth from the fermentation of 
Trichoderma reesei. In addition, ethanol was used to modify the coalescence of air bubbles in water and in model fluids. A preliminary analysis showed that outside the impeller region, the bubble Sauter mean diameter was almost independent on the probe location. This outcome made it possible to estimate $k_{L}$ from the average values of $d_{32}, \alpha_{G}$ and $k_{L} a$. Experimental data were fitted to empirical correlations which estimated the effect of gas velocity, power input per volume unit, and viscosity of the media. The analysis pointed out different results concerning the role of each parameter on mass transfer:

O The effect of power input on $k_{L} a$ is mainly due to its effect on $\alpha_{G}$, and this effect is strengthened by the simultaneous decrease in $d_{32}$ with the dissipated power.

O Similarly, the superficial gas velocity causes an increase in $k_{L} a$ because of the increase in $\alpha_{G}$. However, this effect is partly restrained by the simultaneous increase in $d_{32}$ with the gas flow rate.

○ The effect of viscosity on $k_{L} a$ is primarily due to its effect on $k_{L}$, and this effect is strengthened by the simultaneous increase in $d_{32}$ and decrease in $\alpha_{G}$.

○ The dependency of $k_{L}$ on dissipated power and superficial gas velocity was negligible or below the overall accuracy of the correlation.

O Adding ethanol was a valid method to mimic the effect of surfactants in Trichoderma reesei broths. Additives increased $k_{L} a$, and this phenomenon is explained by the decrease in $d_{32}$ and the increase in $\alpha_{G}$. No influence on $k_{L}$ was observed. 
Data collected in this study and the correlations proposed can provide a valuable contribution to the design and scaleup of agitated fermenters. Bubble size measurements in viscous non-Newtonian fluids can be used, for example, to validate coalescence and drag law models implemented in CFD solvers. For future perspectives, it would be interesting to employ the crosscorrelation technique to characterize the bubble diameter in a large-scale reactor where the presence of spatial heterogeneity poses a significant challenge to the design of industrial units. 


\section{Nomenclature}

$A_{i} \quad$ Surface of the $i$-th bubble, $\mathrm{m}^{2}$

a Specific interfacial area, $\mathrm{m}^{2} \mathrm{~m}^{-3}$

$a_{\text {shape }}$ Prefactor used in Eq. 4

$B \quad$ Length of the baffles, $m$

$C, C^{\prime}$ Coefficients used in Equation 12 and 13

$c_{i} \quad$ Regression coefficient used in Equation 9

$D \quad$ Diameter of the impeller, $\mathrm{m}$

$d \quad$ Inter-probe distance, $\mu \mathrm{m}$

$d_{32} \quad$ Bubble Sauter mean diameter, $\mathrm{m}$

$d_{h, 32}$ Horizontal Sauter mean diameter, m

$d_{v, 32} \quad$ Vertical Sauter mean diameter, $\mathrm{m}$

$\mathcal{D}_{L} \quad$ Oxygen diffusivity in water and model fluids, $\mathrm{m}^{2} \mathrm{~s}^{-1}$

$E \quad$ Bubble eccentricity, $d_{v} / d_{h}$

Eo Eötvös number

$g \quad$ Gravitational acceleration constant, $9.81 \mathrm{~m} \mathrm{~s}^{-2}$

$h_{D} \quad$ Clearance of the turbine, $\mathrm{m}$ 
$h_{S} \quad$ Clearance of the gas sparger, $\mathrm{m}$

$K \quad$ Consistency index, $\mathrm{Pa}^{\mathrm{n}}$

$k_{L} \quad$ Liquid-side mass transfer coefficient, $\mathrm{m} \mathrm{s}^{-1}$

$k_{L} a \quad$ Volumetric mass transfer coefficient, $\mathrm{s}^{-1}$

$N \quad$ Impeller rotation speed, $\mathrm{s}^{-1}$

$n \quad$ Flow behavior index

$N_{P} \quad$ Impeller power number

$P_{0} \quad$ Power input without gas in the system, W

$P_{G} \quad$ Power input in aerated vessel, $\mathrm{W}$

$R_{G} \quad$ Eulerian correlation coefficient

$\frac{P_{G}}{V} \quad$ Volumetric power input, $\mathrm{W} \mathrm{m}^{-3}$

$Q_{G} \quad$ Air flow rate, $\mathrm{m}^{3} \mathrm{~s}^{-1}$

$S_{A}, S_{B}$ Normalized signals carried by the sensor

$T \quad$ Diameter of the tank, $m$

$U_{G} \quad$ Superficial gas velocity $\left(\mathrm{ms}^{-1}\right)$

$V_{i} \quad$ Volume of the $i$-th bubble, $\mathrm{m}^{3}$

\section{Greek symbols}

$\alpha_{G} \quad$ Global gas holdup 
$\dot{\gamma} \quad$ Average shear rate, $\mathrm{s}^{-1}$

$\mu_{a p p} \quad$ Apparent viscosity of the liquid phase, $\mathrm{Pas}^{-1}$

$\nu \quad$ Kinematic viscosity of the liquid phase, $\mathrm{m}^{2} \mathrm{~s}^{-1}$

$\rho \quad$ Density of the continuous phase, $\mathrm{kg} \mathrm{m}^{-3}$

\section{Superscripts and subscripts}

G Gas phase

$h \quad$ Bubble's horizontal axis

L Liquid phase

$v \quad$ Bubble's vertical axis

$0 \quad$ Relative to the unaerated condition

Abbreviations

CC Cross-correlation

CFD Computationl fluid dynamics

CMC Carboxymethyl cellulose

RPD Relative power demand

RSD Relative standard deviation

XG Xanthan gum 


\section{References}

Al-Rubeai, M., et al., 2015. Animal cell culture. Springer.

Alves, S.S., Maia, C.I., Vasconcelos, J., Serralheiro, A.J., 2002. Bubble size in aerated stirred tanks. Chemical Engineering Journal 89, 109-117. doi:10.1016/S1385-8947(02)00008-6.

Amirnia, S., de Bruyn, J.R., Bergougnou, M.A., Margaritis, A., 2013. Continuous rise velocity of air bubbles in non-newtonian biopolymer solutions. Chemical Engineering Science 94, 60-68.

Bach, C., Yang, J., Larsson, H., Stocks, S.M., Gernaey, K.V., Albaek, M.O., Krühne, U., 2017. Evaluation of mixing and mass transfer in a stirred pilot scale bioreactor utilizing CFD. Chemical Engineering Science 171, 19-26.

Barigou, M., Greaves, M., 1992. Bubble-size distributions in a mechanically agitated gas-liquid contactor. Chemical Engineering Science 47, 20092025.

Bhavaraju, S.M., Russell, T., Blanch, H., 1978. The design of gas sparged devices for viscous liquid systems. AIChE Journal 24, 454-466.

Bombač, A., Žun, I., Filipič, B., Žumer, M., 1997. Gas-filled cavity structures and local void fraction distribution in aerated stirred vessel. AIChE journal 43, 2921-2931.

Bouaifi, M., Roustan, M., 1998. Bubble size and mass transfer coefficients in dual-impeller agitated reactors. The Canadian Journal of Chemical Engineering 76, 390-397. 
Bujalski, W., Nienow, A., Chatwin, S., Cooke, M., 1987. The dependency on scale of power numbers of rushton disc turbines. Chemical Engineering Science 42, 317-326.

Calderbank, P., Moo-Young, M., 1961. The continuous phase heat and masstransfer properties of dispersions. Chemical Engineering Science 16, 39-54.

Clift, R., Grace, J.R., Weber, M.E., 2005. Bubbles, drops, and particles. Courier Corporation.

Cox, A.R., Aldred, D.L., Russell, A.B., 2009. Exceptional stability of food foams using class ii hydrophobin hfbii. Food Hydrocolloids 23, 366-376.

Danckwerts, P., 1951. Significance of liquid-film coefficients in gas absorption. Industrial \& Engineering Chemistry 43, 1460-1467.

Delvigne, F., Takors, R., Mudde, R., van Gulik, W., Noorman, H., 2017. Bioprocess scale-up/down as integrative enabling technology: from fluid mechanics to systems biology and beyond. Microbial Biotechnology 10, $1267-1274$.

Gabelle, J.C., 2012. Analyse locale et globale de l'hydrodynamique et du transfert de matière dans des fluides à rhéologie complexe caractéristiques des milieux de fermentation. Ph.D. thesis. Toulouse, INSA.

Gabelle, J.C., Augier, F., Carvalho, A., Rousset, R., Morchain, J., 2011. Effect of tank size on kla and mixing time in aerated stirred reactors with non-newtonian fluids. The Canadian Journal of Chemical Engineering 89, $1139-1153$. 
Gabelle, J.C., Jourdier, E., Licht, R., Chaabane, F.B., Henaut, I., Morchain, J., Augier, F., 2012. Impact of rheology on the mass transfer coefficient during the growth phase of trichoderma reesei in stirred bioreactors. Chemical Engineering Science 75, 408-417.

Garcia-Ochoa, F., Gomez, E., 2009. Bioreactor scale-up and oxygen transfer rate in microbial processes: an overview. Biotechnology Advances 27, 153176.

Gemello, L., Plais, C., Augier, F., Cloupet, A., Marchisio, D., 2018. Hydrodynamics and bubble size in bubble columns: Effects of contaminants and spargers. Chemical Engineering Science 184, 93-102.

Hardy, N., Augier, F., Nienow, A.W., Béal, C., Chaabane, F.B., 2017. Scaleup agitation criteria for Trichoderma reesei fermentation. Chemical Engineering Science 172, 158-168.

Haringa, C., Deshmukh, A.T., Mudde, R.F., Noorman, H.J., 2017. Eulerlagrange analysis towards representative down-scaling of a $22 \mathrm{~m}^{3}$ aerobic S. cerevisiae fermentation. Chemical Engineering Science 170, 653-669.

Ho, C.S., Ju, L.K., Baddour, R.F., 1988. The anomaly of oxygen diffusion in aqueous xanthan solutions. Biotechnology and Bioengineering 32, 8-17.

Kawase, Y., Halard, B., Moo-Young, M., 1987. Theoretical prediction of volumetric mass transfer coefficients in bubble columns for newtonian and non-newtonian fluids. Chemical Engineering Science 42, 1609-1617.

Kawase, Y., Halard, B., Moo-Young, M., 1992. Liquid-phase mass transfer 
coefficients in bioreactors. Biotechnology and Bioengineering 39, 11331140.

Lamont, J.C., Scott, D., 1970. An eddy cell model of mass transfer into the surface of a turbulent liquid. AIChE Journal 16, 513-519.

Lapin, A., Schmid, J., Reuss, M., 2006. Modeling the dynamics of E. coli populations in the three-dimensional turbulent field of a stirred-tank bioreactora structured-segregated approach. Chemical Engineering Science 61, $4783-4797$.

Linek, V., Kordač, M., Fujasová, M., Moucha, T., 2004. Gas-liquid mass transfer coefficient in stirred tanks interpreted through models of idealized eddy structure of turbulence in the bubble vicinity. Chemical Engineering and Processing: Process Intensification 43, 1511-1517.

Linek, V., Kordač, M., Moucha, T., 2005. Mechanism of mass transfer from bubbles in dispersions: part ii: mass transfer coefficients in stirred gasliquid reactor and bubble column. Chemical Engineering and Processing: Process Intensification 44, 121-130.

Machon, V., Pacek, A., Nienow, A., 1997. Bubble sizes in electrolyte and alcohol solutions in a turbulent stirred vessel. Chemical Engineering Research and Design 75, 339-348.

Momiroski, V., Bhattacharya, S., Davoody, M., Abdul Raman, A.A.B., Parthasarathy, R., 2018. Size distribution of bubbles in agitated viscous n ewtonian and non-n ewtonian solutions. Asia-Pacific Journal of Chemical Engineering 13, e2267. 
Montante, G., Horn, D., Paglianti, A., 2008. Gas-liquid flow and bubble size distribution in stirred tanks. Chemical Engineering Science 63, 2107-2118.

Paul, E.L., Atiemo-Obeng, V.A., Kresta, S.M., 2004. Handbook of industrial mixing: Science and practice. John Wiley \& Sons.

Pérez, J.S., Porcel, E.R., López, J.C., Sevilla, J.F., Chisti, Y., 2006. Shear rate in stirred tank and bubble column bioreactors. Chemical Engineering Journal 124, 1-5.

Petříček, R., Moucha, T., Rejl, F.J., Valenz, L., Haidl, J., Čmelíková, T., 2018. Volumetric mass transfer coefficient, power input and gas hold-up in viscous liquid in mechanically agitated fermenters. measurements and scale-up. International Journal of Heat and Mass Transfer 124, 1117-1135.

Pinelli, D., Liu, Z., Magelli, F., 2010. Analysis of kla measurement methods in stirred vessels: the role of experimental techniques and fluid dynamic models. International Journal of Chemical Reactor Engineering 8.

Prasher, B.D., Wills, G.B., 1973. Mass transfer in an agitated vessel. Industrial \& Engineering Chemistry Process Design and Development 12, $351-354$.

Raimundo, P.M., Cartellier, A., Beneventi, D., Forret, A., Augier, F., 2016. A new technique for in-situ measurements of bubble characteristics in bubble columns operated in the heterogeneous regime. Chemical Engineering Science 155, 504-523.

Tchuenbou-Magaia, F., Norton, I., Cox, P., 2009. Hydrophobins stabilised 
air-filled emulsions for the food industry. Food Hydrocolloids 23, 18771885.

Van't Riet, K., 1979. Review of measuring methods and results in nonviscous gas-liquid mass transfer in stirred vessels. Industrial \& Engineering Chemistry Process Design and Development 18, 357-364.

Vazquez, G., Alvarez, E., Navaza, J.M., 1995. Surface tension of alcohol water+ water from 20 to 50. degree. c. Journal of Chemical and Engineering Data 40, 611-614.

Wellek, R., Agrawal, A., Skelland, A., 1966. Shape of liquid drops moving in liquid media. AIChE Journal 12, 854-862.

Zhang, Z., Thomas, C.R., 1995. Eddy number distribution in isotropic turbulence and its application for estimating mass transfer coefficients. Chemical Engineering Communications 140, 207-217. 